\title{
Absence of the trade-off between the size and number of offspring in the natterjack toad (Bufo calamita)
}

\author{
Miguel Tejedo \\ Estación Biológica de Doñana, C.SJ.C., Apdo. 1056, 41080—Sevilla, Spain
}

\begin{abstract}
Summary. A trade-off between size and number of offspring was not found for females of similar sizes of the natterjack toad (Bufo calamita). Moreover, for large females, clutches with higher number of eggs had larger eggs as well. This suggests that larger females produce more numerous and larger eggs because they potentially have more energy available for reproduction. Egg size diminished allometrically with clutch size. Egg size, however, did not increase offspring fitness. Therefore, this allometric decrease may be considered a consequence of phylogenetic constraints rather than a result of optimizing selection.
\end{abstract} Key words: Amphibian Bufo calamita Egg size
Fecundity - Trade-off

The relationship between offspring number and size has been viewed as a matter of compromise by models which predict an optimal balance between both traits (Smith and Fretwell 1974; Brockelman 1975). These models assume that as offspring size increases, clutch size must decrease and that offspring fitness increases with size. McGinley (1989), indicated that a precise determination of the relationships between clutch size, offspring size and offspring fitness, may help to clarify the selective pressures that act on different components of reproductive output. In amphibians lacking parental care, parental investment is usually limited to the yolk which is used as energy for growth and survivorship after hatching (Kaplan 1980). Some authors have shown that some larval fitness traits such as development rate or metamorphic size are correlated with egg size (Kaplan 1980, 1985; Walls and Altig 1986; Berven and Chadra 1988). Other suggestions consider that body size constraints affecting reproductive output may merely explain the inverse trend between size and number of offspring (Vitt and Congdon 1978; Kaplan and Saithe 1979). Moreover, the close dependence of reproductive performance on body size, and the pattern of indeterminate growth found in am- phibians may constitute an additional determinant. This is especially so when the rate of energy devoted to reproduction varies as females become older and larger, with a concomitant decrease in growth rate (Andrews 1979; Ballinger and Congdon 1981).

Here I present data on an analysis of the potential trade-off between clutch and egg size in the natterjack toad (Bufo calamita). This species breeds in temporary ponds of very short duration, and females spawn one large clutch per season. Egg and clutch size are sizecorrelated but egg size degree of dependence is weaker (Tejedo 1992a). The study site was located in the Sierra Morena (province of Córdoba, Spain), and consisted of a set of temporary ponds and flooded grounds. During two consecutive seasons 1987-88, pairs in amplexus were captured and immediately isolated in glass aquaria $(30 \times 20 \times 20 \mathrm{~cm})$ filled with 31 of pond water and some vegetation. The aquaria were placed at the point where the pair had been captured, and maintained until oviposition terminated, normally $12 \mathrm{~h}$ later. Afterwards, the female was processed; body length (BL) was measured to the nearest $0.5 \mathrm{~mm}$, by pressing the subject flat against a plastic grid table. Body weight (BW) was measured, to the nearest $0.5 \mathrm{~g}$, using a $100 \mathrm{~g}$ Pesola spring balance. All females were marked individually and permanently by toe-clipping. Toes were kept frozen for a skeletochronological study in order to determine successive resting lines, providing an estimate of the age of each individual (Tejedo 1989). All averaged values are expressed as $-\mathrm{x} \pm 1$ SD. To estimate fecundity, recently-laid clutches were photographed in the same aquaria with little water to avoid any eggs remaining hidden. Likewise, females were flattened to check that there were no residual eggs. Slides were subsequently projected, and the absolute number of eggs for each clutch was counted. Egg size was averaged by measuring, to the nearest 0.02 $\mathrm{mm}$, the diameter of ten randomly selected eggs from each clutch, using a dissecting microscope. Egg size was always measured at Gosner stage 9-10 (Gosner 1960). Afterwards, each clutch was carefully released into the pond where the amplexed pair was captured. 
2.1

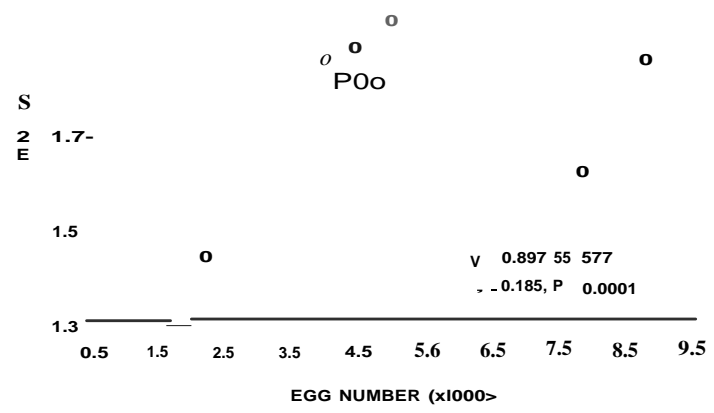

Fig. 1. Relationship between egg size and egg number in females of Bufo calamita

The relationship between the number and the size of eggs in each dutch is shown in Fig. 1. Data belonging to both seasons were pooled because they do not differ in clutch and egg size and moreover, comparison between years revealed that clutch-egg size relationships were similar (ANCOVA, $P>0.05$ ). The trend was positive and significant $\quad\left(\mathrm{y}=0.897 \quad X^{\circ 077}, \quad r 2=0.185\right.$, F59321.14, $P<0.0001)$. An increase in female fecundity implied an allometric decrease in egg size which seemed to tend asymptotically to a maximum. The relationship between egg size and egg number became non-significant when the effect of female body size was partially isolated (partial correlation, BL, $r=-0.131, d f==92, \mathrm{P}>0.20$; and $\mathrm{BW}, r=0.009, d f=92, \mathrm{~F}>0.20)$ or when the effect of age was isolated (partial correlation $r=0.081, d f=38$, $\mathrm{P}>0.20$ ). However, when the analysis was restricted to the larger females $(>72.5 \mathrm{~mm},>31.1 \mathrm{~g})$, a significant positive partial correlation was found (BL, $r=0.319$, $P .<0.05, d f=43$; BW, $r=0.306, P<0.05, d f 42)$. In the smaller females a similar, though non-significant, trend was detected.

The data revealed that there is no negative trade-off between the number of offspring and egg size. Some authors suggest that a trade-off between different components of reproductive output might be expected if there is a body size constraint on reproductive output (Vitt and Congdon 1978; Kaplan and Salthe 1979). This would imply that natterjacks are below maximum physical constraint, and that variations between reproductive properties are mainly determined by factors such as energy availability during vitellogenesis (Kaplan and Saithe 1979). Egg size tended to approach an asymptote as fecundity and body size increased, which might suggest that egg size approaches an optimal size as predicted by models of optimality (Smith and Fretwell 1974; Brockelman 1975; Wilbur 1977). One of the main assumptions of these models is that the amount of energy devoted to reproduction is limited, and hence the existence of an optimum investment level per unit of offspring, but this notion is not universal (van Noordwijk and de Jong 1986). Interestingly, the correlation between egg size and numbers was positive in the larger females which would invalidate the assumption of these models. This same conclusion was found by Semlitsch (1985) in the sala- mauder Ambystoma talpoideum, where a positive correlation between egg and clutch size was found even once body size was removed. A steady increase in energy availability devoted to reproduction in larger females of B. calamita which show a diminution in growth rate (Tejedo 1989) may be responsible for the trend. If larger eggs were optimal, this should imply certain adaptive advantages valued in larval fitness components. Some authors suggest that variation in egg size within or between individuals may be a response to the effect of clutch size on offspring fitness (Parker and Begon 1986; McGinley 1989). However, I failed to find any significant relationship between clutch size and probability of embryo survival in the face of tadpole predation and fungi infection (Tejedo 1991, 1992b). Moreover, egg size variation in natterjacks does not seem to influence larval fitness traits such as growth rate, metamorphic size or survival under different competitive conditions; only hatchling size is dependent on egg size (Tejedo and Regues 1992). Other models by Crump (1981) and Kaplan and Cooper (1984) suggest that in unpredictable environments, like temporary ponds, selection would favor a variation in egg size rather than a simple optimal egg size in response to environmental uncertainty. Lastly egg size might tend to diminish allometrically due to some developmental or phylogenetic constraints (Maynard Smith at al. 1985), while fecundity would increase independently of these processes.

Acknowledgements. I wish to thank Auxiliadora Diaz for her assistance in the field, and Charo Talavera and Borja Sanchiz helped me with the osteochronological study. Dirk Bauwens and two anonymous referees read and commented on an earlier version of the manuscript. This work was partially supported by a grant from the Spanish Research Training Program (P.F.P.L).

\section{References}

Aridrews RM (1979) Reproductive effort of female Anolis liinifons (Sauria:Iguanidae). Copeia 1979:620 626

Ballinger RE, Congdon JD (1981) Population ecology and life history strategy of a Montane Lizard (Sceloporus scalaris) in south-eastern Arizona. J Nat Hut 15:213 222

Broekelman WY (1975) Competition, the fitness of offspring, and optimal clutch size. Am Nat 109:677-699

Crump ML (1981) Variation in propagule size as a function of environmental uncertainty for tree frogs. Am Nat 117:724-737

Gosner KL (1960) A simplified table for staging anuran embryos and larvae with notes on identification. Herpetologica 16:183-190

Kaplan RH (1980) The implications of ovum size variability for offspring fitness and clutch size within several populations of salamanders (Ambystoma). Evolution 34:51-64

Kaplan RH (1985) Maternal influences on offspring development in the California newt, Taricha torosa. Copeia 1985:1028-1035

Kaplan RH, Saithe SN (1979) The allometry of reproduction: an empirical view in salamander. Am Nat 113:671-689

Kaplan RH, Cooper WS (1984) The evolution of developmental plasticity in reproductive characteristics: an application of the “adaptive coin-flipping” principle. Am Nat 123:393-410

Maynard Smith J, Burian R, Kauffman S. Alberch P, Campbell PJ, Goodwin B, Lande R, Raup D, Wolpert L (1985) DevelopmentaL constraints and evolution. Q Rev Biol 60: 265-287

McGinley MA (1989) The influence of a positive correlation between clutch size and offspring fitness on the optimal offspring Size. livol Ecol 3: 150-156 
van Noordwijk AJ, de Jong G (1986) Acquisition and allocation of resources: their influence on variation in life history tactics. Am Nat 128:137-142

Parker GA, Begon M (1986) Optimal egg size and clutch size: effects of environment and maternal phenotype. Am Nat 128:573-592

Semlitsch RD (1985) Reproductive strategy of a facultatively paedomorphic salamander Ambystoma talpoideum. Occologia (Berlin) 65:305-313

Smith CC, Fretwell SD (1974) The optimal balance between size and number of offspring. Am Nat 108:499-506

Tejedo M (1989) Exito reproductor y selección sexual en el sapo corredor, Bufo calamita. PhD thesis, Universidad de Córdoba

Tejedo M (1991) Effect of predation by two species of sympatric tadpoles on embryo survival in nattedack toads (Bufo calamita). Herpetologica 47:322-327

Tejedo M (1992a) Effects of body size and timing of reproduction on reproductive success in female natterjack toads (Bufo calamita, Laurenti, 1768). J Zool (London) (in press)
Tejedo M (1992b) Variability in viability during development and hatching success in embryos of the toad Bufo calamita. Herp J (in press)

Tejedo M, Regues R (1992) Effects of egg size and density on metamorphic traits in tadpoles of the natterjack toad (Bufo calamita) J Herp (in press)

Vitt U, Congdon JD (1978) Body shape, reproductive effort, and relative clutch mass in lizards: resolution of a paradox. Am Nat 112:595-608

Walls SC, Altig R (1986) Female reproductive biology and larval life history of Ambystoma salamanders: a comparison of egg size, hatchling size, and larval growth. Herpetologica 42:334-345

Wilbur HM (1977) Propagule size, number, and dispersion pattern in Ambystoma and Asciepias. Am Nat 111:43 68 